\title{
COVID-19 and HIV Treatment Interruption: A Case Study of the AIDS Support Organization (TASO) Mbale Clinic
}

\author{
Bonniface Oryokot ${ }^{1,2} \mathbb{(}^{\circ}$, Andrew Kazibwe1,3, Abraham Ignatius Oluka1, Yunus Miya1, \\ Michael Bernard Etukoit ${ }^{1}$
}

${ }^{1}$ Directorate of Program Management and Capacity Development, The AIDS Support Organization (TASO), Kampala, Uganda

${ }^{2}$ University of Suffolk, Ipswich, UK

${ }^{3}$ Makerere University College of Health Sciences, Kampala, Uganda

Email: bonory@gmail.com

How to cite this paper: Oryokot, B., Kazibwe, A., Oluka, A.I., Miya, Y. and Etukoit, M.B. (2021) COVID-19 and HIV Treatment Interruption: A Case Study of the AIDS Support Organization (TASO) Mbale Clinic. World Journal of AIDS, 11, 199-215. https://doi.org/10.4236/wja.2021.114015

Received: November 8, 2021

Accepted: December 28, 2021

Published: December 31, 2021

Copyright ( $\odot 2021$ by author(s) and Scientific Research Publishing Inc. This work is licensed under the Creative Commons Attribution International License (CC BY 4.0).

http://creativecommons.org/licenses/by/4.0/

\begin{abstract}
Introduction: COVID-19 pandemic caught many HIV programs completely unprepared, leading to massive interruptions in HIV treatment. Fear and anxiety caused by another infectious and potentially deadly virus kept many PLHIV away from accessing ART services. Besides, the COVID-19 control measures imposed by the Government of Uganda, such as restrictions on movement due to the ban on both private and public transport, shortened travel hours due to the curfew imposed from 7 p.m. local time and limited resources at The AIDS Support Organization (TASO) Mbale clinic further frustrated access to ART services. The actual burden of treatment interruption in Uganda remains unclear. As such, this paper provides the magnitude of treatment interruption in TASO Mbale clinic during the April-June 2020 quarter-the COVID-19 pandemic peak period in Uganda. Methodology: We analyzed secondary and routine program data for all PLHIV on scheduled appointment in the quarters of January-March 2020 and April 2020June 2020. We abstracted data from Uganda Electronic Medical Records (EMR) and linked with that from TASO Management Information system to make one dataset. This was then exported for final analysis in STATA version 15. Results: Out of 6744 PLHIV scheduled on appointment during April-June 2020 quarter, 1710 (25.3\%) individuals missed their appointments, with the facility-based clients more affected than community-based (56.1\% vs $43.9 \%$ ) ( $\mathrm{p}<0.001$ ), individuals with up-to-date viral load (VL) status were less likely to miss their appointment $(\mathrm{p}<0.001)$ while sex was not associated with missed appointment ( $\mathrm{p}$-value $=0.269)$. Overall, there was a $356 \%$ increase in rate of missed appointment compared with that of January-March 2020 quarter (25.3\% vs $7.1 \%$ ) before COVID-19 pandemic hit Uganda. Moreover, PLHIV
\end{abstract}


who received six-month's drug refills were less likely to miss their appointment $(\mathrm{p}<0.001)$ compared to those who received less. Conclusions: The COVID-19 pandemic significantly disrupted provision of ART services, leading to increased rate of missed appointment from $7.1 \%$ in the pre-COVID-19 quarter to $25.3 \%$.

\section{Keywords}

HIV, Treatment Interruption, COVID-19, TASO

\section{Introduction}

The novel coronavirus, SARS-CoV-2, and the associated Corona Virus Disease (COVID-19), described in Wuhan, China in December 2019, resulted in a global health emergency [1] [2]. Many countries in sub-Saharan Africa (SSA) including Uganda, in compliance with World Health Organization (WHO) recommendations [1], first instituted strict lockdown measures on $18^{\text {th }}$ March 2020, as part of the COVID-19 containment measures [3] [4]. These measures included closure of all educational institutions, transport restrictions with total ban on public means of transport and closure of all places that encourage crowding [1] [5]. While the lockdowns aimed at limiting community spread of COVID-19, it also resulted in untold consequences, such as reduced access to medical services including those of HIV, which could negatively influence treatment outcomes [4]. With a fragile healthcare system often constrained by inadequate human resources and logistics, COVID-19 was feared to undermine progress in ending the HIV epidemic in many developing countries such as those in SSA [6]. Moreover, the diversion of healthcare resources to manage COVID-19 patients [7] and the lockdown measures were predicted to further negatively impact HIV service access and utilization. Furthermore, the adverse psychosocial and socioeconomic situations caused by loss of employment and direct impact of COVID-19 [8] could further increase chances of PLHIV missing their scheduled clinic appointments; hence, interrupting treatment. Home to about $66.7 \%$ of global population of people living with HIV (PLHIV) [9], SSA was expected to suffer worst, from the direct and indirect effects of COVID-19 [3] [4]. The effect of HIV care and treatment disruption could lead to increased adverse service outcomes, such as morbidity and mortality among the PLHIV.

Indeed, modeling studies have predicted increased morbidity and death from AIDS-related illnesses in the region [6] [10]. For example, a five-year effect of HIV treatment interruption is predicted to cause $10 \%$ increment in AIDS-related deaths [10] [11]. Similarly, a separate study indicated that a six-month interruption in HIV treatment could cause 1.63 times increase in death in one year [6]. The realization of this chilling prediction could stifle great gains in the HIV fight that have been achieved in SSA, including Uganda. In the case of Uganda, AIDS related mortality had reduced by $58 \%$ by the end of 2019 compared to the 2010 
figures [12]. Besides, 87\% of PLHIV in Uganda knew their status, with $84 \%$ on treatment and 75\% achieving viral suppression by the end of December 2019, which was in line with the global targets of 95-95-95 [12] [13]. It is critical for these gains to be sustained and propelled forwards to realize the global targets of epidemic control. However, for the country to sustain this momentum, PLHIV need to remain in care and on ART without substantial interruptions which may ensure optimal adherence with subsequent viral load suppression [8] [14]. Unfortunately, the COVID-19 pandemic has directly or indirectly caused massive disruptions in HIV services in the country, leading to limited access to antiretroviral therapy (ART) to PLHIV [8]. This may peg back the national and sub-national progress in the race to attain the AIDS epidemic control by 2030 [15].

The international community acknowledges this disturbing fact and has encouraged different countries to innovate strategies that may mitigate its effects [16] [17]. However, for Uganda to effectively circumvent the potential catastrophe posed by the disruptions in HIV services, there is need to appreciate the actual burden of HIV treatment interruptions in the country. To date, there is only a paucity of data indicating the actual burden of HIV treatment interruptions in Uganda following the COVID-19 pandemic, which may frustrate development of appropriate policies to respond to the COVID-19 devastation in HIV services. In consequence, our paper provides evidence on the burden of disengagement of PLHIV in care at The AIDS Support Organization (TASO) Mbale clinic in Eastern Uganda during the April-June 2020 quarter, the COVID-19 Pandemic peak period in Uganda. This will contribute to the existing body of knowledge to guide policy in the implementation of client-centered HIV care services in response to calls by UNAIDS and WHO for governments to develop context specific COVID-19 counter measures.

\section{Methodology}

\subsection{Study Design}

A retrospective cohort study design was used and routine program data from April 2020 to June 2020 was analyzed. In addition, program data of PLHIV clients who were on scheduled appointment in that period were analyzed to identify the magnitude of missed appointment, and re-engagement of PLHIV after disengagement. Similarly, data for the January 2020-March 2020 quarter for purposes of comparisons were analyzed.

\subsection{Study Site}

The AIDS Support Organization (TASO) Mbale is a Center of Excellence (CoE) providing comprehensive HIV prevention, care and treatment services [18]. TASO Mbale is a specialized HIV clinic located inside Mbale Regional Referral Hospital approximately 230 kilometers east of Kampala Capital City. The CoE operates in the districts of Mbale, Sironko, Bududa, Namisindwa, Manafwa, Bukedea, Ki- 
buku, Budaka, Pallisa and Butebo, covering a diameter of 75 kilometers [9]. The services are provided through a differentiated service delivery model (DSDM)s, with about $70 \%$ of the PLHIV served in the community and about $30 \%$ from the facility. DSDMs included facility-based individual management (FBIM), Fasttrack drug refills (FTDR), Facility-based groups (FBG), Community-client-led ART delivery (CCLAD), Community drug delivery points (CDDPs) [19] [20] [21]. Both CCLAD and CDDPs are based in the community and all PLHIV receive their drugs from designated locations within their localities. The clinic operates normally from Monday to Friday, 08:00-17:30 hours East African Standard time. Finally, individuals received ART in a multi-month approach, with drugs dispensed for one month, two months, three months, four months, five months and six months respectively, depending on the clinical status of a client [17] [22].

\subsection{Study Population}

All the PLHIV on ART, registered at TASO Mbale clinic and scheduled to receive services from the $1^{\text {st }}$ April, 2020 to $30^{\text {th }}$ June, 2020, and those scheduled on appointment from the $1^{\text {st }}$ January, 2020 to $31^{\text {st }}$ March, 2020 for purposes of comparison. These individuals were expected to receive HIV services from both the facility and community.

\subsection{Data Management}

Routine patient monitoring raw data were extracted from Uganda Electronic Medical Records (EMR) version 3.0.4 using inbuilt cohort builder module capabilities. Clients with any return visit dates between April 2020 and June 2020 were extracted from Uganda EMR with basic patient characteristics like age, sex and service point. Specifically, up to date viral load data was generated and extracted from TASO Management Information Systems with restrictions to only viral load (VL) done in the last 12 months. Data from Uganda EMR and TASO MIS were then linked and merged into one dataset. Preliminary data cleaning was done in MS-Excel and MS-Access interchangeably and the final cleaned dataset was exported to STATA CORP version 15 for analysis.

Descriptive statistics were conducted in order to determine basic patient characteristics. At bivariate level, Pearson chi-square tests were performed to test for relationships between missed appointments and different independent variables such as sex, age group and service point. Statistically, significant independent variables were also tested for the same using simple logistic regression model where unadjusted odds ratios were reported. Furthermore, a multivariate logistic regression model was conducted to identify factors associated with missed appointments adjusted for confounding and multicollinearity. To estimate the maximum likely influence of the different independent factors on the dependent variable, logistic regression model was preferred because of a binary outcome variable. The statistical level of significance was set at 0.05 . 


\subsection{Measurements}

The outcome variable was the missed appointment defined as any PLHIV who did not turn up on their scheduled appointment. It was measured on a binary scale of yes or no. Therefore, individuals who kept their appointments were considered as active while those who missed appointment were considered as disengaged. However, those individuals who came back to care after missing their appointment were considered as re-engaged. The independent variables were age group, service point (described as the point where a PLHIV receives ART services either from the facility or community), multi-month dispensing (MMD), sex and viral load status.

\section{Results}

As demonstrated in Table 1, a total of 6744 patients scheduled for clinical services at TASO Mbale CoE during the quarter of April to June 2020, 4647 (68.9\%) were females and 2097 (31.1\%) males. In terms of service point, 4220 (62.6\%) were scheduled to access their comprehensive HIV services from the community while 2524 (37.4\%) were supposed to be reviewed at the facility. The vast majority of our patients were adults $(5982,88.7 \%)$ aged 25 years or older while the children, adolescents and the youths constituted $2 \%, 5.9 \%$ and $3.4 \%$ respectively.

Out of the 6744 patients on scheduled appointment during the quarter, 1710 (25.3\%) patients missed their appointment including 1160 (67.8\%) females and $550(32.2 \%)$ males. Importantly, more patients 960 (56.1\%) missed at the facility than in the community $(750,43.9 \%)$. Comparatively, in the quarter of January to March 2020, out of 7279 patients on scheduled appointment, only 519 missed their appointments, translating to $7.1 \%$. Multi-month drug refills were strongly associated with missed appointment (P-value $<0.001)$.

From Table 2, 337 (19.7\%) patients were followed and provided with services while $18(1.1 \%)$ deaths were recorded and 7 clients were transferred out to other facilities during this period. Majority of the patients $(1348,78.8 \%)$ were yet to be followed up and statuses determined.

From Table 3, it can be seen that age group is associated with missed appointment $(\mathrm{P}$-value $<0.001)$ and service point $(\mathrm{P}$-value $<0.001)$ while sex was not associated with missed appointment $(\mathrm{P}$-value $=0.269)$. Moreover, it was found that individuals with an up-to-date viral load result (within 12 months before study period) were less likely to miss their appointment compared to those without $(\mathrm{P}<0.001)$.

From Table 4, the columns of results of the unadjusted ratios show that age group, service point, viral load status and multi-months drug dispensing respectively were statistically significant $(\mathrm{P}<0.05)$ in influencing missed appointments. Specifically, the youths (20 - 24 years) were 2.13 times more likely to miss appointments as compared to children ( 0 - 9 years) $(\mathrm{OR}=2.13$; 95\% C. I [1.3111 - 3.4636]; $\mathrm{P}<0.001)$. Relatedly, PLHIV receiving ART services from facility arm 
Table 1. Showing basic patient characteristics.

\begin{tabular}{|c|c|c|c|c|}
\hline \multirow[b]{2}{*}{ Variable } & \multicolumn{2}{|c|}{ Scheduled Appointments } & \multicolumn{2}{|c|}{ Missed Appointments } \\
\hline & $\begin{array}{l}\text { Frequency } \\
(n=6744)\end{array}$ & $\begin{array}{c}\text { Percent } \\
(\%)\end{array}$ & $\begin{array}{l}\text { Frequency } \\
(n=1710)\end{array}$ & $\begin{array}{c}\text { Percent } \\
(\%)\end{array}$ \\
\hline \multicolumn{5}{|c|}{ Period } \\
\hline April_20 & 2872 & 42.6 & 704 & 41.2 \\
\hline June_20 & 2137 & 31.7 & 346 & 20.2 \\
\hline May_20 & 1735 & 25.7 & 660 & 38.6 \\
\hline Jan_20-March_20 & 7279 & 100 & 519 & 7.1 \\
\hline \multicolumn{5}{|c|}{ Age group (Years) } \\
\hline Children (0 - 9) & 132 & 2 & 30 & 1.8 \\
\hline Adolescents (10 - 19) & 399 & 5.9 & 73 & 4.3 \\
\hline Youths $(20-24)$ & 231 & 3.4 & 89 & 5.2 \\
\hline Adults $(\geq 25)$ & 5982 & 88.7 & 1518 & 88.8 \\
\hline \multicolumn{5}{|c|}{ Sex } \\
\hline Female & 4647 & 68.9 & 1160 & 67.8 \\
\hline Male & 2097 & 31.1 & 550 & 32.2 \\
\hline \multicolumn{5}{|c|}{ Service point } \\
\hline Community & 4220 & 62.6 & 750 & 43.9 \\
\hline Facility & 2524 & 37.4 & 960 & 56.1 \\
\hline \multicolumn{5}{|c|}{ Viral load status } \\
\hline No VL result & 880 & 13.1 & 437 & 25.6 \\
\hline Suppressed & 5515 & 81.8 & 1159 & 67.8 \\
\hline Non-suppressed & 349 & 5.2 & 114 & 6.7 \\
\hline \multicolumn{5}{|c|}{ Multi Month Dispensation of drugs } \\
\hline 1 Month & 236 & 3.5 & 119 & 7.0 \\
\hline 2 Months & 251 & 3.7 & 115 & 6.7 \\
\hline 3 Months & 2794 & 41.4 & 992 & 58.0 \\
\hline 4 Months & 62 & 0.9 & 13 & 0.8 \\
\hline 5 Months & 20 & 0.3 & 5 & 0.3 \\
\hline$\geq 6$ Months & 3381 & 50.1 & 466 & 27.3 \\
\hline
\end{tabular}

Table 2. Showing patients followed up and status determined.

\begin{tabular}{ccc}
\hline Variable & Frequency $(\mathrm{n}=1710)$ & Percent $(\%)$ \\
\hline Returned to care & Follow-up status & \\
Died & 337 & 19.7 \\
Lost & 18 & 1.1 \\
Transferred out & 1348 & 78.8 \\
\hline
\end{tabular}


Table 3. Showing some factors associated with missed appointment during the peak of COVID-19 control measures at TASO Mbale (chi-square tests).

\begin{tabular}{|c|c|c|c|}
\hline \multirow{2}{*}{ Variable } & \multicolumn{2}{|c|}{ Missed appointment } & \multirow[b]{2}{*}{ P-Value } \\
\hline & No & Yes & \\
\hline \multicolumn{4}{|c|}{ Age group (Years) } \\
\hline Children $(0-9)$ & 102 & 30 & \multirow{4}{*}{$<0.001^{*}$} \\
\hline Adolescents (10 - 19) & 326 & 73 & \\
\hline Youths $(20-24)$ & 142 & 89 & \\
\hline Adults $(\geq 25)$ & 4464 & 1518 & \\
\hline \multicolumn{4}{|c|}{ Sex } \\
\hline Female & 3487 & 1160 & \multirow{2}{*}{0.269} \\
\hline Male & 1547 & 550 & \\
\hline \multicolumn{4}{|c|}{ Service point } \\
\hline Community & 3470 & 750 & \multirow{2}{*}{$<0.001^{*}$} \\
\hline Facility & 1564 & 960 & \\
\hline \multicolumn{4}{|c|}{ Viral load status } \\
\hline No VL result & 443 & 437 & \multirow{3}{*}{$<0.001^{*}$} \\
\hline Suppressed & 4356 & 1159 & \\
\hline Unsuppressed & 235 & 114 & \\
\hline
\end{tabular}

${ }^{\star}$ Significant $(\mathrm{P}<0.05)$.

Table 4. Showing unadjusted and adjusted logistic regression (testing for likelihood of missing appointment).

\begin{tabular}{|c|c|c|c|c|c|c|c|c|}
\hline \multirow{2}{*}{$\begin{array}{c}\text { Variable } \\
\text { Age group (Years) }\end{array}$} & \multicolumn{4}{|c|}{ Unadjusted } & \multicolumn{4}{|c|}{ Adjusted } \\
\hline & \multirow{2}{*}{$\begin{array}{c}\text { Odds ratio } \\
1\end{array}$} & P-Value & \multicolumn{2}{|c|}{$\begin{array}{c}\text { [95\% confid. } \\
\text { Interval] }\end{array}$} & \multirow{2}{*}{$\begin{array}{c}\text { Odds ratio } \\
1\end{array}$} & P-Value & \multicolumn{2}{|c|}{$\begin{array}{l}\text { [95\% confid. } \\
\text { Interval] }\end{array}$} \\
\hline Children $(0-9)$ & & & & & & & & \\
\hline Adolescents (10 - 19) & 0.76 & 0.27 & 0.4712 & 1.23 & 0.84 & 0.49 & 0.5183 & 1.3732 \\
\hline Youths $(20-24)$ & 2.13 & $<0.001^{*}$ & 1.3111 & 3.4636 & 2.42 & $<0.001^{*}$ & 1.4663 & 3.9975 \\
\hline Adults $(\geq 25)$ & 1.16 & 0.49 & 0.7664 & 1.7443 & 2.79 & $<0.001^{*}$ & 1.8181 & 4.2724 \\
\hline \multicolumn{9}{|l|}{ Sex } \\
\hline Female & 1 & & & & 1 & & & \\
\hline Male & 1.07 & 0.27 & 0.9499 & 1.2024 & 1.02 & 0.81 & 0.894 & 1.154 \\
\hline \multicolumn{9}{|l|}{ Service point } \\
\hline Community & 1 & & & & 1 & & & \\
\hline Facility & 2.84 & $<0.001^{*}$ & 2.5374 & 3.1785 & 1.82 & $<0.001^{*}$ & 1.5872 & 2.0943 \\
\hline \multicolumn{9}{|l|}{ VL status } \\
\hline No VL result & 1 & & & & 1 & & & \\
\hline Suppressed & 0.27 & $<0.001^{*}$ & 0.2328 & 0.3125 & 0.42 & $<0.001^{*}$ & 0.3593 & 0.4949 \\
\hline Unsuppressed & 0.49 & $<0.001^{\star}$ & 0.3792 & 0.6377 & 0.54 & $<0.001^{*}$ & 0.4105 & 0.7181 \\
\hline
\end{tabular}


Continued

\begin{tabular}{|c|c|c|c|c|c|c|c|c|}
\hline \multicolumn{9}{|c|}{ Multi-month drug dispensed } \\
\hline 1 Month & 6.36 & $<0.001^{*}$ & 4.841 & 8.3617 & 3.78 & $<0.001^{*}$ & 2.7916 & 5.1218 \\
\hline 2 Months & 5.29 & $<0.001^{*}$ & 4.0506 & 6.9072 & 4.25 & $<0.001^{*}$ & 3.1609 & 5.7094 \\
\hline 3 Months & 3.44 & $<0.001^{*}$ & 3.0397 & 3.9012 & 2.79 & $<0.001^{*}$ & 2.4289 & 3.2048 \\
\hline 4 Months & 1.66 & 0.109 & 0.8934 & 3.0827 & 1.22 & 0.54 & 0.6477 & 2.2859 \\
\hline 5 Months & 2.09 & 0.157 & 0.7543 & 5.7642 & 1.51 & 0.43 & 0.5381 & 4.2438 \\
\hline$\geq 6$ Months & 1 & & & & & & & \\
\hline
\end{tabular}

${ }^{*}$ Significant $(\mathrm{P}<0.05)$.

were 2.84 times more likely to miss their scheduled appointments compared to their counterparts in the community $(\mathrm{OR}=2.84 ; 95 \%$ [2.5374 - 3.1785] $\mathrm{P}<$ 0.001). As regards their viral load status in the last 12 months, results also depicted that clients with suppressed viral load in the past 12 months were $73 \%$ less likely to miss their appointments as compared to those who had never been bled for viral load (OR $=0.73$; 95\% C.I [0.2328 - 0.3125]); $\mathrm{P}<0.001)$. Additionally, clients with unsuppressed VL in the past 12 months were $51 \%$ less likely to miss their scheduled appointments as compared to their counterparts who have never been monitored for VL in the last 12 months $(\mathrm{OR}=0.51$; C.I [0.3792 - 0.6377] $\mathrm{P}$ $<0.001)$. In the same vein, clients who received ART for one month, two months and three months, respectively were three or more times more likely to miss their scheduled appointments compared to those who received ART for 6 or more months $(\mathrm{OR}=6.36,5.29,3.44$; 95\% C.I [4.8410 - 8.3617]; [4.0506 - 6.9072]; [3.0397 - 3.9012] $\mathrm{P}<0.001)$. On the contrary, sex was found to be insignificant in influencing missed appointments $(\mathrm{P}>0.05)$.

Further, the multivariate results from the columns of the adjusted odds ratios suggest that age group, service point and VL status are statistically significant influencers of missed appointments $(\mathrm{P}<0.05)$. Precisely, adults aged 25 years and above were 2.79 times more likely to miss their scheduled appointments as compared to children less than 10 years of age $(\mathrm{OR}=2.79,95 \%$ CI $[1.8181$ 4.2724]; $\mathrm{P}<0.001$ ). The youths were 2.42 times more likely to miss their scheduled appointments as compared to the children less than 10 years of age $(\mathrm{OR}=$ 2.42; 95\% C.I [1.4663 - 3.9975]; P < 0.001). Moreover, the adjusted ratios consistently suggest that clients receiving their ART care services from the facility were 1.82 times more likely to miss their scheduled visits as compared to their colleagues receiving treatment from the community arm $(\mathrm{OR}=1.82$; 95\% C.I [1.5872 - 2.0943] $\mathrm{P}<0.001)$. As per the VL status, clients with suppressed VL in the last 12 months were $58 \%$ less likely to miss their appointments as compared to their counterparts without any VL results in the past 12 months $(\mathrm{OR}=0.58$; 95\% C.I [0.3593 - 0.4949] P < 0.001). Furthermore, those with unsuppressed VL results in the past 12 months were $46 \%$ less likely to miss their scheduled appointments when compared to their colleagues who were not bled for VL in the last 12 months $(\mathrm{OR}=0.46 ; 95 \%$ C.I $[0.4105-0.7181] \mathrm{P}<0.001)$. The results also 
showed that clients who received ART for one month, two months and three months, respectively were two or more times more likely to miss their scheduled appointments compared to those who received ART for 6 or more months (OR = 2; 95 C.I [2.7916 - 5.1218]; [3.1609 - 5.7094]; [2.4289 - 3.2048] P < 0.001). Therefore, six-month refills could potentially provide for continued engagement of PLHIV in care. At multivariate level, sex was not a significant influencer of missed appointments in the period of study, which is consistent with previous results from chi-square and unadjusted ratios $(\mathrm{P}>0.05)$

\section{Discussions}

In this study, we found that 1710 (25.3\%) out of 6744 PLHIV on scheduled appointment during the April-June 2020 quarter missed their clinic encounters at TASO Mbale clinic compared to just $7.1 \%$ during the preceding quarter of January-March 2020. The PLHIV most likely to miss their clinic encounters were those without an up-to-date viral load test done in the previous twelve months before the period $(\mathrm{P}<0.05)$, those who were in the facility model of treatment compared to those served through the community arms $(\mathrm{P}<0.001)$, youths aged 20 - 24 years compared to other age groups $(\mathrm{P}<0.001)$, and those who received less than 6 months of drugs at their last clinic visit $(P<0.001)$. There were no significant gender differences observed. Overall, there was a 356\% increment in the missed appointment rate compared with the 7.1\% (519/7279) experienced during the January-March 2020 quarter.

High rate of missed appointment among the PLHIV during this quarter could be attributed to increased clinical, psychological and structural barriers to accessing HIV treatment services, such as increased transport costs and transport lockdown restrictions, and perceived risk of increased COVID-19 exposure from health facilities as was described by Nalubega et al. and Linnemayr et al. [23] [24]. Our finding is supported by a Chinese study that indicated that $32.6 \%$ of PLHIV could potentially miss their drugs and $48.6 \%$ were unsure of where or how to access the much-needed lifesaving ART during the lockdown [3]. Another study in the United States of America (US) reported rescheduling 30\% of the 98 PLHIV on appointment during the first four weeks (March 21-April 17) of the COVID-19 peak in Chicago [25]. Furthermore, many HIV clinics reduced working hours to beat the curfew imposed by the Government of Uganda which further curtailed access to ART related services [7]. In addition, some key health workers were absorbed into the COVID-19 task force while others worked from home; thus, limiting service provision [7]. In TASO Mbale, like other health facilities in Uganda at the time, volunteers and students on academic placement in the facility were all asked to stay home. This resulted in further increased workload on the already limited available workforce. Importantly, domestic violence cases spiked during the lockdown restrictions with women living with HIV disproportionately affected and this further hampered their abilities to access HIV care services. For example, in South Africa, 67000 cases of domestic violence 
were reported in the first week of the COVID-19 lockdown [26].

Relatedly, this study revealed that facility-based clients were more likely to miss their appointment than their community-based counterparts; hence, suffering greater treatment interruption. From the study results, it can be concluded that the transport restrictions could have contributed significantly to this situation because TASO Mbale clinic provides services to individuals as far away from the facility as $75 \mathrm{~km}$. In addition, it was perhaps easier to mobilize clients in their community groups using telephone calls directly to individual clients and through their leaders as well. As a result, the use of telemedicine has been highly recommended in the wake of the COVID-19 pandemic and even before, especially in improving retention among the PLHIV in care [27] [28]. Our finding supports the findings by Zakumumpa et al. that the COVID-19 pandemic revived interest in community ART delivery models in Uganda, as part of efforts to sustain treatment services among PLHIV. He describes important modifications to and intensified implementation of traditional community drug delivery models such as home-based ART delivery, drug pick-up at Community Drug Distribution Points (CDDPs) and provision of longer treatment refills [29]. This further emphasizes the effectiveness of differentiated service delivery models of HIV care [30] [31] [32], which includes reduced geographic barriers, access to peer support, flexible services, client-centeredness and increased health systems efficiency [30] [33] [34] that are crucial in ensuring favorable HIV treatment outcomes such as viral load suppression, and less likelihood of PLHIV developing drug resistance, which is highly prevalent in Uganda [35] [36]. Similarly, many HIV programs in Western Kenya adopted community approach to HIV care [7] to relieve pressure on the health system and reduce the waiting time for clients who seek HIV treatment services [21] [37] [38]. This is probably the main reason Lodge and Kuchukhidze recommended the scale up of community-based HIV treatment services to mitigate the immense and anticipated disruptions caused by COVID-19 [14].

The study found that youths aged 20 - 24 compared to children aged 0 - 9 years, had higher odds of missing their clinic appointments. Although this study could not find any findings that compared retention among the youths and children younger than 10 years, many reported equally lower retention rates among the groups compared to other age groups. For example, studies from Kenya and Thailand reported that the attrition rate was double among the youths compared to young adolescents aged $10-14$ years old [39] [40]. This is why it is not surprising that a large study involving PLHIV aged 10 years or older in four SSA countries of Kenya, Mozambique, Rwanda and Tanzania found the highest rates of attrition among the youths when compared with young adolescents [41]. Socioeconomic factors have been described as key barriers to continued engagement in care among the youths. These include geographical (urban vs rural) factors, low social support systems, low income status and non-disclosure of HIV status [41] [42]. It is thus, important for HIV programs to design inter- 
ventions and services that are youth-friendly in order to maintain them in care.

Unlike several reports from previous studies indicating higher attrition rate among men than women [43] [44] [45] [46], we did not find significant gender differences in burden of missed appointments. However, it is important to note that those studies were conducted nearly a decade ago, yet there have been many interventions to close this gender disparity over the same period [22]. For example, TASO has been implementing differentiated service delivery model of HIV care for more than a decade now [19] and this could have provided men with similar treatment experiences in the clinic.

Furthermore, our study also found that viral load status was associated with the likelihood of attrition. Individuals who had an up-to-date VL status were less likely to miss their appointment compared with those without $(\mathrm{P}<0.001)$. There were no studies found reporting similar findings. However, it could be theorized that PLHIV who attend clinic visits with fidelity are likely to have their VL tests done compared to those who irregularly do so. This position is corroborated by the fact that majority of those without current VL results were in the facility arm (560 vs 320). Hence, this finding concretizes the call for enhanced community interventions for PLHIV.

Finally, clients who received a three- to a six-month's ART refills seemed less likely to experience missed appointment. Termed as MMD, many policymakers have recommended its use to counter the rampant missed appointments among the PLHIV [17] [22] [34] and improve overall retention in care of clients. Indeed, PLHIV who received ART refills for three months or less were more likely to miss their scheduled appointments than those who were refilled for six months or more $(P<0.001)$. It can be theorized that clients who received few drug refills have to visit the clinic more frequently, potentially experiencing greater economic costs, especially in the era of COVID-19 pandemic where transport costs are much higher than before compared with those whose appointments were more spaced. MMD ART refills are considered a key component of PLHIV centered care and the President's Emergency Plan for AIDS Relief (PEPFAR) has consistently recommended its increased uptake to scale to avert the catastrophic impact of COVID-19 on client retention [17] [47]. Therefore, a six-month's ART refills appears to provide hope in reducing missed appointment schedules among the PLHIV, which could lead to the betterment of these individuals' engagements in care. Nevertheless, there is a continued call to different HIV programs to ensure continuity of services as the COVID-19 situation continues to terrorize countries [48].

\section{Strengths of the Study}

This study used routine program data, which potentially provides a true reflection of the situation on the ground.

\section{Study Limitations}

The use of secondary data denied us the chance to obtain patient perspective on 
actual reasons for missing their scheduled appointments. This, therefore, presents an opportunity for a future study to consider this element of the study. Furthermore, this study only focused on one facility which means the findings may not necessarily be representative of the national situation. However, we believe the findings fairly represent the general national picture as all HIV service providers were similarly affected across the country. Also, this study does not describe the impact of the pandemic on patient treatment outcomes such as morbidity, mortality and viral load suppression. Further studies are required involving bigger sample sizes and with longitudinal follow up of clients to provide further information on the long-term impacts of the COVID-19 pandemic on chronic HIV care.

\section{Conclusion}

1) The COVID-19 pandemic significantly interrupted HIV care as demonstrated by clients missing their scheduled appointment especially during the peak of COVID-19 pandemic in the country.

2) It was also found that MMD, specifically the six-month's refills of ART appear to provide better engagement of the PLHIV in care.

3) Community-based PLHIV were less likely to miss their appointment than their facility-based counter-parts.

\section{Recommendation}

1) Overall, chronic disease programs should adapt flexible service delivery models to ensure resilience in case of emergency of pandemics that restrict patient physical access to health care facilities. Therefore, different programs need to innovate or adapt strategies in order to mitigate HIV treatment interruptions.

2) There is need to encourage different HIV programs to adopt the MMD because it reduces treatment interruptions. The six-month's refills particularly sappear to offer more favorable outcomes.

3) Furthermore, more resources need to be directed to retention. Clearly, the pandemic has and most likely, will continue to cause treatment interruptions. Therefore, it is going to be more costly to retain PLHIV in care than before the pandemic.

4) Lastly, it is necessary to adopt community-based HIV services across different age groups. This offers less treatment interruptions, so more focus and resources need to be directed towards community HIV programming. This will require more meaningful involvement of HIV peers which have been demonstrated to be effective elsewhere including in Prevention of Mother to Child Transmission of HIV [49] [50] [51] [52].

\section{Acknowledgements}

We appreciate the USAID RHITES-E mechanism, through INTRAHEALTH and Ministry of Health-Uganda for providing financial and technical guidance to TASO Mbale clinic. We also sincerely thank TASO Uganda senior manage- 
ment and Mr. Gordon Karukomain particular for supporting publication of this study. In addition, Mr. Ceaser Godfrey Mafabi and the entire management team of TASO Mbale is appreciated for their unwavering efforts in supporting TASO Mbale clients and making this study a reality. Finally, we appreciate Mr. Sebastian Jalameso of National Curriculum Development Center (Uganda) for editing this work.

\section{Conflicts of Interest}

The authors declare no conflicts of interest regarding the publication of this paper.

\section{References}

[1] WHO (World Health Organization) (2020, March 7) Responding to Community Spread of COVID-19. Interim Guidance, 1-6.

https://www.who.int/publications/i/item/responding-to-community-spread-of-covi $\underline{\mathrm{d}-19}$

[2] WHO (World Health Organization) (2020) Infection Prevention and Control Guidance for Long-Term Care Facilities in the Context of COVID-19. Interim Guidance. World Health Organization, 1-5. https://apps.who.int/iris/handle/10665/331508

[3] Nyoni, T. and Okumu, M. (2020) COVID-19-Compliant Strategies for Supporting Treatment Adherence among People Living with HIV in Sub-Saharan Africa. AIDS and Behavior, 24, 1-4. https://doi.org/10.1007/s10461-020-02888-0

[4] Mhango, M., Chitungo, I. and Dzinamarira, T. (2020) COVID-19 Lockdowns: Impact on Facility-Based HIV Testing and the Case for the Scaling Up of Home-Based Testing Services in Sub-Saharan Africa. AIDS and Behavior, 24, 3014-3016. https://doi.org/10.1007/s10461-020-02939-6

[5] Aimua, E.P. and Paul, J. (2021) Covid-19 and the Educational Sector: Challenges and the Need for Inclusive Education in Nigeria. Asian Journal of Economics, Business and Accounting, 21, 15-23. https://doi.org/10.9734/ajeba/2021/v21i530377

[6] Jewell, B.L., Mudimu, E., Stover, J., ten Brink, D., Phillips, A.N., Smith, J.A., et al. (2020) Potential Effects of Disruption to HIV Programmes in Sub-Saharan Africa Caused by COVID-19: Results from Multiple Mathematical Models. Lancet HIV, 7 , e629-e640. https://doi.org/10.1016/S2352-3018(20)30211-3

[7] Lagat, H., Sharma, M., Kariithi, E., Otieno, G., Katz, D., Masyuko, S., et al. (2020) Impact of the COVID-19 Pandemic on HIV Testing and Assisted Partner Notification Services, Western Kenya. AIDS and Behavior, 24, 3010-3013. https://doi.org/10.1007/s10461-020-02938-7

[8] Pinto, R.M. and Park, S. (2020) COVID-19 Pandemic Disrupts HIV Continuum of Care and Prevention: Implications for Research and Practice Concerning Community-Based Organizations and Frontline Providers. AIDS and Behavior, 24, 24862489. https://doi.org/10.1007/s10461-020-02893-3

[9] Oryokot, B., Miya, Y., Logose, B., Ajambo, E., Oluka, A., Odoi, C., et al. (2020) Interventions to Improve HIV Viral Load Suppression among the Adolescents: Evidence of Improvement Science through a Quality Improvement Approach in Eastern Uganda. World Journal of AIDS, 10, 94-106. https://doi.org/10.4236/wja.2020.102008

[10] Hogan, A.B., Jewell, B.L., Sherrard-Smith, E., Vesga, J.F., Watson, O.J., Whittaker, C., et al. (2020) Potential Impact of the COVID-19 Pandemic on HIV, Tuberculosis, 
and Malaria in Low-Income and Middle-Income Countries: A Modelling Study. The Lancet Global Health, 8, e1132-e1141. https://doi.org/10.1016/S2214-109X(20)30288-6

[11] The Lancet (2020) Maintaining the HIV Response in a World Shaped by COVID19. The Lancet, 396, 1703. https://doi.org/10.1016/S0140-6736(20)32526-5 https://pubmed.ncbi.nlm.nih.gov/33248482/

[12] UAC (Uganda Aids Commission) (2019) Uganda Aids Commission Facts on HIV and Aids in Uganda 2020.

[13] United Nations Joint Programme on HIV/AIDS (UNAIDS) (2019) Country Factsheets Uganda. 2019 HIV and AIDS Estimates Adults and Children. United Nations Joint Programme on HIV/AIDS (UNAIDS), Geneva, 1-10.

[14] Lodge, W. and Kuchukhidze, S. (2020) COVID-19, HIV, and Migrant Workers: The Double Burden of the Two Viruses. AIDS Patient Care and STDs, 34, 249-250. https://doi.org/10.1089/apc.2020.0092

[15] Walker, J. (2016) Achieving Health SDG 3 in Africa through NGO Capacity Building-Insights from the Gates Foundation Investment in Partnership in Advocacy for Child and Family Health (PACFaH) Project. African Journal of Reproductive Health, 20, 55-61. https://doi.org/10.29063/ajrh2016/v20i3.10

[16] Golin, R., Godfrey, C., Firth, J., Lee, L., Minior, T., et al. (2020) PEPFAR's Response to the Convergence of the HIV and COVID-19 Pandemics in Sub-Saharan Africa. Journal of the International AIDS Society, 23, Article ID: e25587. https://doi.org/10.1002/jia2.25587

[17] U.S. President's Emergency Plan for AIDS Relief (PEPFAR) (2020) PEPFAR Technical Guidance in Context of COVID-19 Pandemic. Washington DC, 1-36.

[18] TASO (The AIDS Support Organization) (2017) TASO Strategic Plan 2018-2022. The AIDS Support Organization, Uganda.

[19] The AIDS Support Organization (TASO) (2016) Community Client-Led ART Delivery Model (CCLAD). The AIDS Support Organization, Uganda, 6.

[20] Sarah, K., Julie, R., Julian, H. and Andrew, E. (2011) Cases in Global Health Delivery: The AIDS Support Organization (TASO) of Uganda. No. 44, Harvard Business Publishing, Boston, 1-36.

[21] Ministry of Health of Uganda (2020) National Training Curriculum for Roll Out of the Consolidated Guidelines for the Prevention and Treatment of HIV and Aids in. Ministry of Health of Uganda, Kampala.

[22] U.S. President's Emergency Plan for AIDS Relief (PEPFAR) (2020) PEPFAR 2020 Country Operational Plan Guidance for All PEPFAR Countries. PEPFAR, Washington DC.

[23] Nalubega, S., Kyenkya, J., Bagaya, I., Nabukenya, S., Ssewankambo, N., Nakanjako, D., et al. (2021) COVID-19 May Exacerbate the Clinical, Structural and Psychological Barriers to Retention in Care among Women Living with HIV in Rural and Peri-Urban Settings in Uganda. BMC Infectious Diseases, 21, Article No. 980. https://doi.org/10.1186/s12879-021-06684-6

[24] Linnemayr, S., Jennings Mayo-Wilson, L., Saya, U., Wagner, Z., MacCarthy, S., Walukaga, S., et al. (2021) HIV Care Experiences during the COVID-19 Pandemic: Mixed-Methods Telephone Interviews with Clinic-Enrolled HIV-Infected Adults in Uganda. AIDS and Behavior, 25, 28-39. https://doi.org/10.1007/s10461-020-03032-8

[25] Ridgway, J.P., Schmitt, J., Friedman, E., Taylor, M., Devlin, S., McNulty, M., et al. (2020) HIV Care Continuum and COVID-19 Outcomes among People Living with 
HIV during the COVID-19 Pandemic, Chicago, IL. AIDS and Behavior, 24, 27702772. https://doi.org/10.1007/s10461-020-02905-2

[26] Joska, J.A., Andersen, L., Rabie, S., Marais, A., Ndwandwa, E.S., Wilson, P., et al. (2020) COVID-19: Increased Risk to the Mental Health and Safety of Women Living with HIV in South Africa. AIDS and Behavior, 24, 2751-2753. https://doi.org/10.1007/s10461-020-02897-z

[27] Mgbako, O., Miller, E.H., Santoro, A.F., Remien, R.H., et al. (2020) COVID-19, Telemedicine, and Patient Empowerment in HIV Care and Research. AIDS and Behavior, 24, 1990-1993. https://doi.org/10.1007/s10461-020-02926-x

[28] Hermans, S.M., Elbireer, S., Tibakabikoba, H., Hoefman, B.J. and Manabe, Y.C. (2017) Text Messaging to Decrease Tuberculosis Treatment Attrition in TB-HIV Coinfection in Uganda. Patient Preference and Adherence, 11, 1479-1487. https://doi.org/10.2147/PPA.S135540

[29] Zakumumpa, H., Tumwine, C., Milliam, K. and Spicer, N. (2021) Dispensing Antiretrovirals during Covid-19 Lockdown: Re-Discovering Community-Based ART Delivery Models in Uganda. BMC Health Services Research, 21, Article No. 692. https://doi.org/10.1186/s12913-021-06607-w

[30] ICAP (2017) ICAP Approach to Differentiated Service Delivery. ICAP, New York, p. 7.

https://cquin.icap.columbia.edu/wp-content/uploads/2017/07/ICAP CQUIN ICAP Approach to DSD July2017.pdf

[31] Kandasami, S., Shobiye, H., Fakoya, A., Asiimwe, S., Inimah, M., Etukoit, M., et al. (2019) Can Changes in Service Delivery Models Improve Program Quality and Efficiency? A Closer Look at HIV Programs in Kenya and Uganda. JAIDS Journal of Acquired Immune Deficiency Syndromes, 81, 533-539. https://doi.org/10.1097/QAI.0000000000002064

[32] WHO (World Health Organization) (2016) Meeting report Consultation on HIV Differentiated Service Delivery Models for Specific Populations and Settings: Pregnant and Breastfeeding Women, Children, Adolescents and Key Populations. World Health Organization, Geneva, 2-4.

http://www.who.int/hiv/pub/meetingreports/DSDmeetingreportJan122017.pdf

[33] Eshun-Wilson. I., Mukumbwa-Mwenechanya, M., Kim, H.Y., Zannolini, A., Mwamba, C.P., Dowdy, D., et al. (2019) Differentiated Care Preferences of Stable Patients on Antiretroviral Therapy in Zambia: A Discrete Choice Experiment. JAIDS Journal of Acquired Immune Deficiency Syndromes, 81, 540-546.

https://doi.org/10.1097/QAI.0000000000002070

[34] MOH-Uganda (Ministry of Health of Uganda) (2017) Implementation Guide for Differentiated Service Delivery of HIV Services in Uganda. Ministry of Health of Uganda, Kampala.

[35] Kityo, C., Boerma, R.S., Sigaloff, K.C.E., Kaudha, E., Calis, J.C.J., Musiime, V., et al. (2017) Pretreatment HIV Drug Resistance Results in Virological Failure and Accumulation of Additional Resistance Mutations in Ugandan Children. Journal of Antimicrobial Chemotherapy, 72, 2587-2595. https://doi.org/10.1093/jac/dkx188

[36] WHO (World Health Organization) (2019) Preventing and Responding to HIV Drug Resistance in the African Region: Regional Action Plan 2019-2023. World Health Organization, Brazzaville.

[37] MOH-Uganda (Ministry of Health of Uganda) (2018) Consolidated Guidelines on the Prevention and Treatment of HIV. Ministry of Health of Uganda, Kampala.

[38] World Health Organization (2016) Consolidated Guidelines on the Use of Antiretro- 
viral Drugs for Treating and Preventing HIV Infection. World Health Organization, Geneva.

[39] Emily Koecha, E.J.A., Teasdalea, C.A., Wanga, C., Fayorseya, R., Alwara, T., Mukuic, I.N. and Hawkena, M. (2016) Characteristics and Outcomes of HIV-Infected Youth and Young Adolescents Enrolled in HIV Care in Kenya. AIDS, 28, 2729-2738. https://doi.org/10.1097/QAD.0000000000000473

[40] Teeraananchai, S., Puthanakit, T., Kerr, S.J., Chaivooth, S., Kiertiburanakul, S., Chokephaibulkit, K., et al. (2019) Attrition and Treatment Outcomes among Adolescents and Youths Living with HIV in the Thai National AIDS Program. Journal of Virus Eradication, 5, 33-40. https://doi.org/10.1016/S2055-6640(20)30276-4

[41] Lamb, M.R., Fayorsey, R., Nuwagaba-Biribonwoha, H., Viola, V., Mutabazi, V., Alwar, T., et al. (2014) High Attrition before and after ART Initiation among Youth (15-24 Years of Age) Enrolled in HIV Care. AIDS, 28, 559-568. https://doi.org/10.1097/QAD.0000000000000054

[42] Colasanti, J., Stahl, N., Farber, E.W., Del Rio, C. and Armstrong, W.S. (2017) An Exploratory Study to Assess Individual and Structural Level Barriers Associated with Poor Retention and Re-Engagement in Care among Persons Living with HIV/AIDS. JAIDS Journal of Acquired Immune Deficiency Syndromes, 74, S113-S120. https://doi.org/10.1097/QAI.0000000000001242

[43] Cornell, M., Schomaker, M., Garone, D.B., Giddy, J., Hoffmann, C.J., Lessells, R., et al. (2012) Gender Differences in Survival among Adult Patients Starting Antiretroviral Therapy in South Africa: A Multicentre Cohort Study. PLoS Medicine, 9, e1001304. https://doi.org/10.1371/journal.pmed.1001304

[44] Hawkins, C., Chalamilla, G., Okuma, J., Spiegelman, D., Hertzmark, E., Aris, E., et al. (2011) Sex Differences in Antiretroviral Treatment Outcomes among HIV-Infected Adults in an Urban Tanzanian Setting. AIDS, 25, 1189-1197. https://doi.org/10.1097/QAD.0b013e3283471deb

[45] Ochieng-Ooko, V., Ochieng, D., Sidle, J.E., Holdsworth, M., Wools-Kaloustian, K., Siika, A.M., et al. (2010) Influence du sexe de la personne sur la perte du suivi dans un vaste programme de traitement du VIH dans l'ouest du Kenya. Bulletin of the World Health Organization, 88, 681-688. https://doi.org/10.2471/BLT.09.064329

[46] Kranzer, K., Lewis, J.J., Ford, N., Zeinecker, J., Orrell, C., Lawn, S.D., et al. (2010) Treatment Interruption in a Primary Care Antiretroviral Therapy Program in South Africa: Cohort Analysis of Trends and Risk Factors. Journal of Acquired Immune Deficiency Syndromes, 55, 17-23. https://doi.org/10.1097/QAI.0b013e3181f275fd

[47] PEPFAR (The U.S. President's Emergency Plan for AIDS Relief) (2020) PEPFAR 2021 Country and Regional Operational Plan (COP/ROP) Guidance for all PEPFAR Countries. PEPFAR, Washington DC, 1-487.

https://www.state.gov/wp-content/uploads/2020/12/PEPFAR-COP21-Guidance-Fin al.pdf

[48] Hightow-Weidman, L., Muessig, K., Claude, K., Roberts, J., Zlotorzynska, M. and Sanchez, T. (2020) Maximizing Digital Interventions for Youth in the Midst of Covid-19: Lessons from the Adolescent Trials Network for HIV Interventions. AIDS and Behavior, 24, 2239-2243. https://doi.org/10.1007/s10461-020-02870-w

[49] Igumbor, J.O., Ouma, J., Otwombe, K., Musenge, E., Anyanwu, F.C., Basera, T., et al. (2019) Effect of a Mentor Mother Programme on Retention of Mother-Baby Pairs in HIV Care: A Secondary Analysis of Programme Data in Uganda. PLoS ONE, 14, e0223332. https://doi.org/10.1371/journal.pone.0223332

[50] Choko, A.T., Nanfuka, M., Birungi, J., Taasi, G., Kisembo, P. and Helleringer, S. 
(2018) A Pilot Trial of the Peer-Based Distribution of HIV Self-Test Kits among Fishermen in Bulisa, Uganda. PLoS ONE, 13, e0208191.

https://doi.org/10.1371/journal.pone.0208191

[51] Inzaule, S.C., Hamers, R.L., Kityo, C., Rinke De Wit, T.F. and Roura, M. (2016) LongTerm Antiretroviral Treatment Adherence in HIV-Infected Adolescents and Adults in Uganda: A Qualitative Study. PLoS ONE, 11, e0167492.

https://doi.org/10.1371/journal.pone.0167492

[52] ICAP (2019) Infant HIV Testing Implementation Guide for Programme Managers. ICAP, New York.

https://icap.columbia.edu/tools resources/infant-hiv-testing-guide/ 